\title{
Clinical and Oncological Outcomes of Laparoscopic Versus Open Surgery for Advanced Rectal Cancer
}

\author{
TAKASHI NONAKA, AKIKO FUKUDA, KYOICHIRO MAEKAWA, \\ SHIGEKI NAGAYOSHI, TAKAYUKI TOKUNAGA, MITSUHISA TAKATSUKI, \\ TOMOO KITAJIMA, KEN TANIGUCHI and HIKARU FUJIOKA
}

Department of Surgery, National Hospital Organization Nagasaki Medical Center, Nagasaki, Japan

\begin{abstract}
Aim: To compare the clinical and oncological outcomes of laparoscopic and open approaches in patients with advanced rectal cancer. Patients and Methods: In this study, 78 patients who underwent surgery for advanced middle and lower rectal cancer (pStage II - III) were divided into two groups according to type of surgical approach: laparoscopic surgery (LS group; $n=40)$ and open surgery (OS group: $n=38$ ). The clinical outcomes and oncological outcomes were compared between the two groups. Results: The operation time was comparable, whereas operative blood loss and complication rates were significantly less in the LS group compared to the OS group. Cancer-specific survival (CSS) and local recurrence-free survival (LRFS) were similar in the two groups. Disease-free survival (DFS) was better in the LS group than in the OS group. Conclusion: LS for advanced rectal cancer was safe and not inferior to OS in clinical and oncological outcomes.
\end{abstract}

Laparoscopic surgery (LS) for colorectal cancer has been shown to be a feasible and safe technology, which has spread widely with improved techniques and updated surgical instruments (1-4). Some randomized trials for colorectal cancer surgery have demonstrated that LS provides equivalent oncologic outcomes to open surgery (OS) $(1,5$ $8)$. Although many patients with colon cancer and/or early rectal cancer were enrolled in these studies, LS, particularly for middle and lower rectal cancer, remains controversial because of technical challenges; these include difficulties in pelvic exposure and preservation of sphincter muscles and autonomic nerves during total mesorectal excision (TME).

Correspondence to: Takashi Nonaka, Department of Surgery, National Hospital Organization Nagasaki Medical Center, 2-10011 Kubara, Ohmura, Nagasaki 856-8562, Japan. Tel: +81 957523121, Fax: +81957540292, e-mail: tnonaka@ nagasaki-u.ac.jp

Key Words: Laparoscopic surgery, rectal cancer, advanced stage, total mesorectal excision.
With regard to the oncologic outcomes, these studies were not persuasive enough for the limited cases with rectal cancer, especially for middle and lower rectal cancer (1, 59). Laparoscopic rectal surgery is still not recommended as the treatment of choice in the National Comprehensive Cancer Network Guidelines ver. 2015 (10). Therefore, gastroenterological surgeons are eager to determine whether LS for middle and lower rectal cancer can truly achieve adequate tumor clearance and has equivalent oncologic outcomes when compared with OS, though it has the principal advantages of a clearer magnified view, reduced wounding, less interference to the immune system and faster postoperative recovery (11-13).

The present retrospective study was performed to compare surgical and oncologic outcomes of LS and OS for middle and lower rectal cancer.

\section{Patients and Methods}

A total of 103 patients underwent resection for advanced middle and lower rectal cancer in Nagasaki Medical Center between January 2008 and December 2014. After excluding 25 patients with remote metastases, double cancers, one with squamous rectal cancer and one with recurrent disease, 78 cases with middle and lower rectal cancer ( $\leq 10 \mathrm{~cm}$ from the anal verge) were finally enrolled in the present study (laparoscopic surgery group (LS group); $n=40$, open surgery group ((OS group); $n=38)$. Operative procedures were low anterior resection (LAR), intersphincteric resection (ISR) or abdominoperineal resection (APR). The operative approach, either laparoscopic or open, was decided at the surgeon's discretion considering tumor characteristics and the patient's preference. All surgeries were performed by four experienced surgeons. In particular, laparoscopic surgery was performed by trained surgeons with wide experience in laparoscopic colorectal cancer.

In patients with clinical T4Nx or huge tumor spread near the anal canal, neoadjuvant chemotherapy (NAC) or neoadjuvant chemoradiotherapy (NACRT) was performed based on the decision of a multidisciplinary team conference. Particularly, in the case that circumferential resection margin (CRM) was threatened, chemoradiotherapy (CRT) was selected. Lateral pelvic node dissection (LPND) was indicated when pelvic node metastasis was suspected on preoperative magnetic resonance imaging (MRI). 
Extended TME (E-TME) was defined as en bloc resection of the adjacent organs outside the mesorectal fascia, which was indicated in cases with severe, locally advanced rectal cancer involving the circumference. Medical records of all enrolled patients were reviewed retrospectively, including patients' characteristics, surgical outcomes, postoperative complications, postoperative hospital stay and oncological outcomes.

These variables were compared between the LS and OS groups All $p$-values $<0.05$ were considered significant. The $\chi^{2}$ test (or Fisher's exact test when appropriate) and the Mann-Whitney $U$-test were used for analyses of categorical variables and continuous variables, respectively. Overall survival probability was estimated according to the Kaplan-Meier method, whereas differences between groups were compared by the log-rank test.

This study was conducted according to the Ethical Guidelines of the Nagasaki Medical Center Ethical Committee.

\section{Results}

Clinicopathological features of patients. The medical records of 78 patients (40 patients in LS group and 38 patients in the OS group) were reviewed (Table I). No significant differences were found between the groups in terms of age, sex and body mass index. The percentages of patients who received neoadjuvant or adjuvant CRT were also similar between the two groups (neoadjuvant therapy, 10.0\% $(n=4)$ in the LS group and $7.9 \%(n=3)$ in the OS group; adjuvant chemotherapy, $35.0 \%(n=14)$ in the LS group and $34.2 \%$ $(n=13)$ in the OS group) (Table I). Postoperative pathology findings, including pTNM classification, maximal tumor diameter, cell differentiation grade, depth of tumor invasion and vessel invasion, were not significantly different between the two groups (Table II).

Operative results. There was no conversion to OS in LS. The rate of LPND was similar between the two groups, while ETME was more frequently performed in the LS group than in the OS group $(10.0 \%(\mathrm{n}=4)$ vs. $2.6 \%(\mathrm{n}=1), p=0.32)$. There was no significant difference in the operation time between the groups, while operative blood loss was significantly less in the LS group than in the OS group (119.8.1 $\pm 136.0 \mathrm{ml} v s .429 .0 \pm 251.6 \mathrm{ml}$, respectively, $p<0.01$ ). The rate of sphincter preservation was $87.5 \%$ (35/40) in the LS group and $50.0 \%(19 / 38)$ in the OS group; the difference was significant $(p<0.01)$ (Table III).

Surgical complications. Four (10.0\%) and $17(44.7 \%)$ patients experienced postoperative complications in the LS and OS groups, respectively; the incidence rate was significantly lower in the LS group $(p<0.01)$. There was no perioperative mortality in the two groups. Ileus was more common in the OS group $(n=5)$, while it was not seen in the LS group. The rates of surgical site infections (SSIs) and anastomotic leakage were lower in the LS group but the difference was not significant. Postoperative hospital stay
Table I. Patients' demographics.

\begin{tabular}{lccc}
\hline Parameter & OS (n=38) & LS (n=40) & $p$ \\
\hline Age (years) & 66.0 & 67.9 & 0.58 \\
Gender (M/F) & $19 / 19$ & $28 / 12$ & 0.07 \\
BMI $\left(\mathrm{kg} / \mathrm{m}^{2}\right)$ & 21.7 & 22.1 & 0.24 \\
Neoadjuvant therapy & $3(7.9 \%)$ & $4(10.0 \%)$ & 0.94 \\
Adjuvant chemotherapy & $13(34.2 \%)$ & $14(35.0 \%)$ & 0.94 \\
Using Oxaliplatin & $2(5.3 \%)$ & $4(10.0 \%)$ & 0.71 \\
\hline
\end{tabular}

LS, Laparoscopic surgery group; OS, open surgery group; BMI, body mass index.

Table II. Pathological parameters of tumors.

\begin{tabular}{lccc}
\hline Parameter & OS (n=38) & LS (n=40) & $p$ \\
\hline $\begin{array}{l}\text { pTNM classification (II/III) } \\
\text { Maximal tumor diameter (mm) }\end{array}$ & $57(18 \sim 100)$ & $50(15 \sim 100)$ & 0.25 \\
$\begin{array}{l}\text { Differentiation grades } \\
\text { (well•mod/por/muc) }\end{array}$ & $29 / 6 / 3$ & $26 / 5 / 9$ & 0.19 \\
$\begin{array}{l}\text { Depth of tumor invasion } \\
\text { (T2/T3/T4a/T4b) }\end{array}$ & $6 / 28 / 2 / 2$ & $1 / 37 / 2 / 0$ & 0.41 \\
$\begin{array}{l}\text { Vessel invasion } \\
\text { ly (0/1/2/3) }\end{array}$ & $4 / 22 / 11 / 1$ & $3 / 26 / 10 / 1$ & 0.89 \\
v (0/1/2/3) & $6 / 13 / 14 / 5$ & $7 / 14 / 14 / 5$ & 0.81 \\
\hline
\end{tabular}

LS, Laparoscopic surgery group; OS, open surgery group.

Table III. Operative and postoperative outcomes.

\begin{tabular}{lccc}
\hline & OS (n=38) & LS (n=40) & $p$ \\
\hline Operation time (min) & $345.3 \pm 135.6$ & $316.8 \pm 103.4$ & 0.51 \\
Operative blood loss (ml) & $429.0 \pm 251.6$ & $119.8 \pm 136.0$ & $<0.01$ \\
Sphincter-preserving surgery (\%) & $50.0 \%$ & $87.5 \%$ & $<0.01$ \\
Pelvic lymph node dissection & $13(34.2 \%)$ & $16(40.0 \%)$ & 0.77 \\
Pelvic organ resection performed & $1(2.6 \%)$ & $4(10.0 \%)$ & 0.32 \\
Postoperative complications & $17(44.7 \%)$ & $4(10.0 \%)$ & $<0.01$ \\
Ileus & 4 & 0 & \\
Surgical site infection & 3 & 1 & \\
Anastomotic leakage & 4 & 2 & \\
Urinary incontinence & 1 & 0 & \\
Postoperative hospital stay (day) & 23 & 14 & $<0.01$ \\
\hline
\end{tabular}

LS, Laparoscopic surgery group; OS, open surgery group.

was significantly shorter in the LS group than in the OS group (14 days $v s .23$ days, respectively, $p<0.01$ ) (Table III).

Oncological outcomes (Figures 1, 2 and 3). Short-term follow-up was carried out; median follow-up was 32 months (range $=5-53$ ) in the LS group and 51 months (range=4-66) in the OS group. Neither wound nor port-site recurrence was 


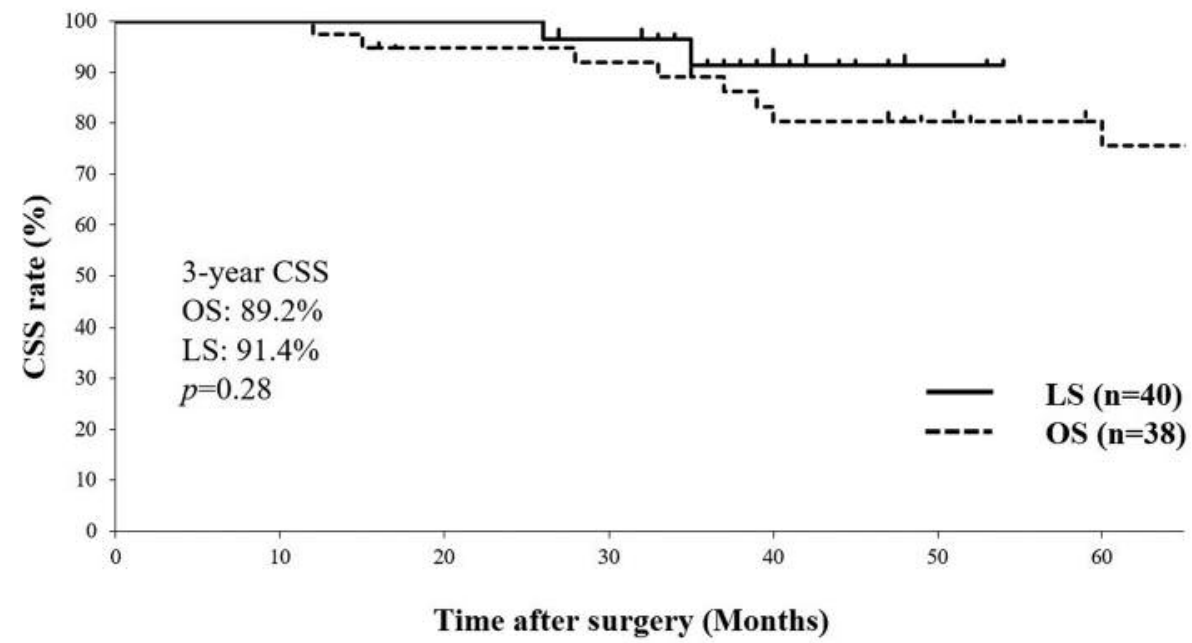

Figure 1. Cancer-specific survival (CSS) of advanced middle and lower rectal cancer patients (pStage II-III). LS, Laparoscopic surgery group; OS, open surgery group.

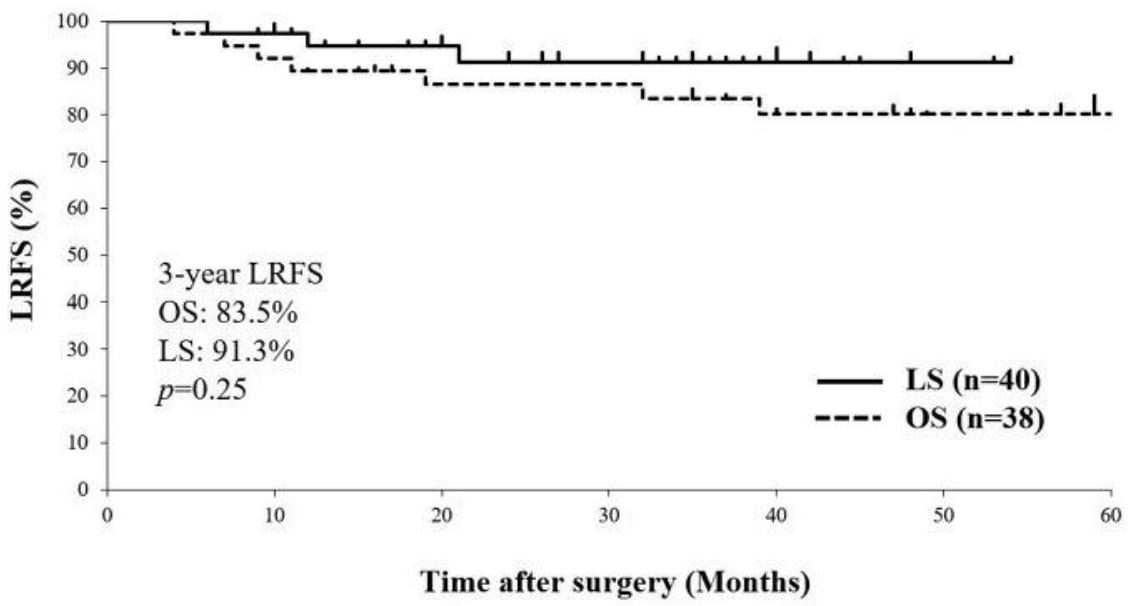

Figure 2. Local recurrence-free survival (LRFS) of advanced middle and lower rectal cancer patients (pStage II-III). LS, Laparoscopic surgery group; OS, open surgery group.

detected in either group. Cancer-specific survival (CSS), local recurrence-free survival (LRFS) and disease-free survival (DFS) were better in the LS group than in the OS group, but there were no significant differences. The 3-year CSS rates of the LS and OS groups were $91.4 \%$ and $89.2 \%(p=0.28)$, the 3 -year LRFS rates were $91.3 \%$ and $83.5 \%(p=0.25)$, whereas the 3-year DFS rates were $81.1 \%$ and $62.2 \%(p=0.10)$ in the LS and OS groups, respectively (Figures 1-3).

\section{Discussion}

LS yields more cosmetic incisions, less analgesic requirements and earlier return to patients' activities, which have been usually accepted by laparoscopic surgeons in early upper rectal cancer $(14,15)$. Although more and more rectal cancer cases have undergone LS by experienced surgeons, there is still skepticism of its appropriateness for lower rectal cancer because of technically demanding procedures for pelvic exposure and TME with the autonomic nerves preserved, etc. $(16,17)$. Therefore, the role of LS, especially for advanced middle and lower rectal cancer, is heatedly debated. However, few analyses have addressed this issue specifically among patients with middle and lower rectal cancer (18-20). The present study compared the applicability and feasibility of LS with OS for middle and lower rectal cancer. 


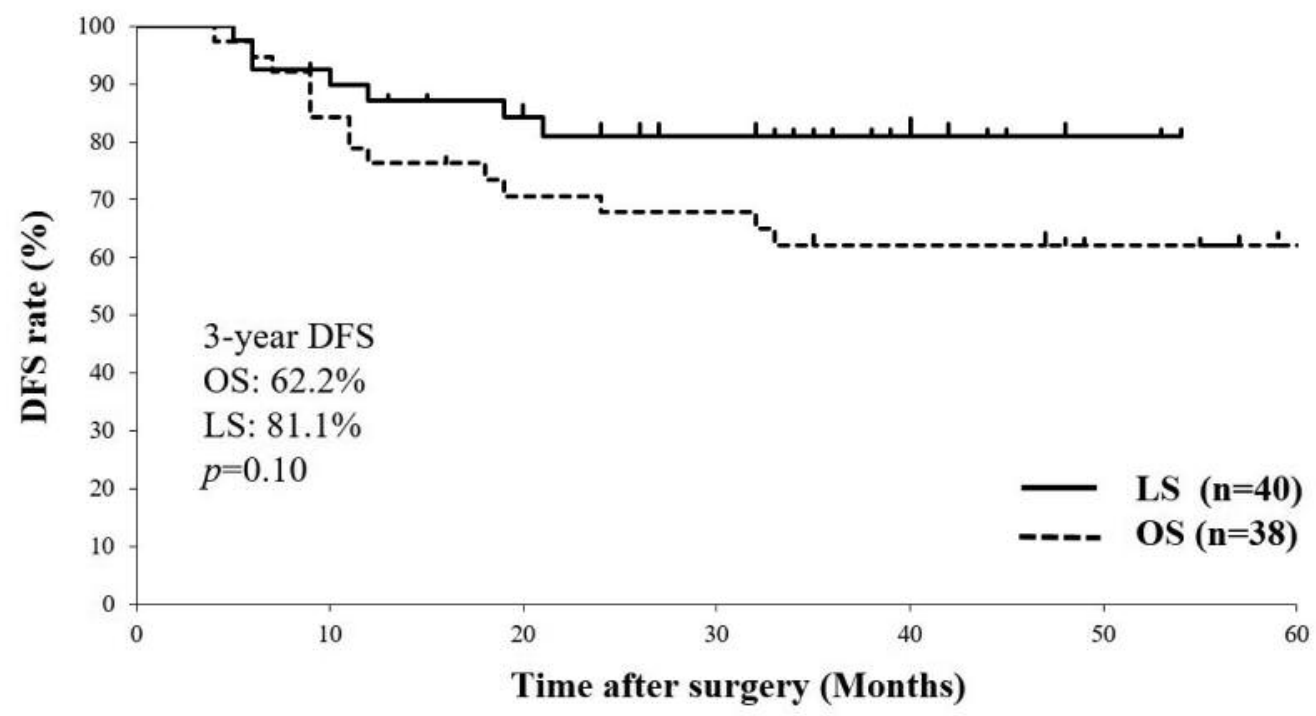

Figure 3. Disease-free survival (DFS) of advanced middle and lower rectal cancer patients (pStage II-III). LS, laparoscopic surgery group; OS, open surgery group.

In this study, patients' demographics and pathological parameters of rectal cancers were similar in the two groups. Although recent conversion rates for laparoscopic resection of rectal cancer have been between 2.8\% and 9.8\% (21-23), there were no conversions in the present study. LS for middle and lower rectal cancer is usually performed by a team led by an endoscopic surgical specialist certified by the Japan Society of Endoscopic Surgery. In addition, these findings reflect the importance of experience and a specialized team to perform LS for middle and lower rectal cancer, although it is well-documented that the leading reasons for conversion to OS included extensive abdominal metastasis, over-sized tumors and a confused anatomic relationship due to serious pelvic adhesions, etc. $(3,12,24)$

The present study demonstrated that LS and OS shared similarities in terms of operation time, extent of resection and pelvic lymph node dissection. In addition, LS also had significantly less estimated blood loss and a better sphincterpreserving rate. This finding can probably be attributed to the fact that operators benefit from the magnified and clear view of laparoscopy in the narrow pelvic cavity, which is advantageous for the preservation of autonomic nerves and TME; it is possible to clearly visually recognize the boundary between the autonomic nerves and mesorectal fascia in the deep pelvis. LS has the potential to improve the accuracy of TME. The reinforcement of TME with understanding of the mesorectum has led to fewer positive margins and, consequently, fewer local recurrences (25). Larsen et al. (26) reported that, in T4a rectal tumors, if we had performed an ordinary TME operation instead of an extended one, there would have been $\mathrm{R} 1 / \mathrm{R} 2$ resections in
$43 \%$ of patients. In terms of local control of the tumor, the extended operation with the laparoscope is useful in advanced lower rectal cancer.

It has been reported that postoperative complications did not differ significantly between OS and LS (27). On the other hand, Gao et al. (28) found that the overall morbidity rate was significantly lower in LS than in OS. In the present study, the rates of postoperative complications (postoperative ileus and SSI rates) were lower in the LS group. From the perspective of SSI, LS was superior to OS in terms of less destruction of the body wall. In addition, postoperative hospital stay was significantly shorter in the LS group than in the OS group.

Although there were no significant differences in postoperative survival rates (CSS, LRFS, DFS), LS was a good tendency. Neither wound nor port-site recurrence was detected, similar to other reports (data not shown) $(2,23)$. This indicates that LS is not inferior to OS in terms of oncological outcomes. Lacy et al. $(29,30)$ reported that oncological outcomes were better in laparoscopic colectomy only for patients with pStage III colon cancer; however, for pStages I and II colon cancers, they were similar for the two operations. It has been postulated that better preservation of cellular immunity and attenuation of the systemic inflammatory response associated with the laparoscopic approach may explain the better survival observed after laparoscopic colorectal surgery $(31,32)$.

There were several limitations in the present study. First, due to the limited sample size, only 78 patients were enrolled, which may have diminished the ability to distinguish the potential difference between the two groups 
studied. Second, this study was retrospectively conducted at a single institution. Selection bias might exist, although the similar patients' characteristics of the two groups suggest no significant impact on the surgical and oncologic outcomes. Lastly, only short-term, not long-term, results were reported because the median follow-up time was less than 5 years. Future randomized, controlled trials are required to elucidate the oncologic advantage of LS for advanced middle and lower rectal cancer.

\section{Conclusion}

LS for middle and lower rectal cancer was superior in surgical qualities and not inferior in oncologic outcomes to OS. In the future, LS should become a standard surgical modality for middle and lower rectal cancer because of its intrinsic advantages, equipment developments and specialization of surgeons.

\section{References}

1 Jayne DG, Thorpe HC, Copeland J, Quirke P, Brown JM and Guillou PJ: Five-year follow up of the Medical Research Council CLASICC trial of laparoscopically assisted versus open surgery for colorectal cancer. Br J Surg 97: 1638-1645, 2010.

2 Law WL, Lee YM, Choi HK, Seto CL and Ho JW: Impact of laparoscopic resection for colorectal cancer on operative outcomes and survival. Ann Surg 245: 1-7, 2007.

3 Guillou PJ1, Quirke P, Thorpe H, Walker J, Jayne DG, Smith AM, Heath RM and Brown JM: MRC CLASICC trial group Short-term endpoints of conventional versus laparoscopicassisted surgery in patients with colorectal cancer (MRC CLASICC trial): multicentre, randomized controlled trial. Lancet 365: 1718-1726, 2005

4 Bretagnol F, Lelong B, Laurent C, Moutardier V, Rullier A, Monges G, Delpero JR and Rullier E: The oncological safety of laparoscopic total mesorectal excision with sphincter preservation for rectal carcinoma. Surg Endosc 19: 892-896, 2005.

5 Veldkamp R, Kuhry E, Hop WC, Jeekel J, Kazemier G, Bonjer HJ, Haglind E, Påhlman L, Cuesta MA, Msika S, Morino M and Lacy AM: Colon Cancer Laparoscopic or Open Resection Study Group (COLOR). Laparoscopic surgery versus open surgery for colon cancer: short-term outcomes of a randomized trial. Lancet Oncol 6: 477-484, 2005.

6 Kang SB, Park JW, Jeong SY, Nam BH, Choi HS, Kim DW, Lim SB, Lee TG, Kim DY, Kim JS, Chang HJ, Lee HS, Kim SY, Jung KH, Hong YS, Kim JH, Sohn DK, Kim DH and Oh JH: Open versus laparoscopic surgery for mid or low rectal cancer after neoadjuvant chemoradiotherapy (COREAN trial): Shortterm outcomes of an open-label randomized controlled trial. Lancet Oncol 11: 637-645, 2010.

7 Fleshman J, Sargent DJ, Green E, Anvari M, Stryker SJ, Beart RW Jr, Hellinger M, Flanagan R Jr., Peters W and Nelson $\mathrm{H}$ : Laparoscopic colectomy for cancer is not inferior to open surgery based on 5-year data from the COST study group trial. Ann Surg 246: 655-662, 2007.
8 Pugliese R, Di Lernia S, Sansonna F, Scandroglio I, Maggioni D, Ferrari GC, Costanzi A, Magistro C and De Carli S: Results of laparoscopic anterior resection for rectal adenocarcinoma: retrospective analysis of 157cases. Am J Surg 195: 233-238, 2008.

9 Braga M, Frasson M, Vignali A, Zuliani W, Capretti G and Di Carlo V: Laparoscopic resection in rectal cancer patients: outcome and cost-benefit analysis. Dis Colon Rectum 50: 464$471,2007$.

10 NCCN Clinical Practice Guidelines on Oncology (NCCN Guidelines). Rectal Cancer. Version 2. (2015).

11 Huang C, Huang R, Jiang T, Huang K, Cao J and Qiu Z: laparoscopic and open resection for colorectal cancer: an evaluation of cellular immunity. BMC Gastroenterol 10: 127, 2010.

12 Zeng WG, Zhou ZX, Hou HR, Liang JW, Zhou HT, Wang Z, Zhang XM and Hu JJ: Outcome of laparoscopic versus open resection for rectal cancer in elderly patients. J Surg Res 193: 613-618, 2015.

13 Wang YW, Huang LY, Song CL, Zhuo CH, Shi DB, Cai GX, Xu Y, Cai SJ and Li XX: Laparoscopic vs. open abdominoperineal resection in the multimodality management of low rectal cancers. World J Gastroenterol 21: 10174-10183, 2015.

14 Law WL, Poon JT, Fan JK and Lo SH: Comparison of outcome of open and laparoscopic resection for stage II and stage III rectal cancer. Ann Surg Oncol 16: 1488-1493, 2009.

15 Lee SD, Park SC, Park JW, Kim DY, Choi HS and Oh JH: Laparoscopic versus open surgery for stage I rectal cancer: Long-term oncologic outcomes. World J Surg 37: 646-651, 2013.

16 Morino M, Parini U, Giraudo G, Salval M, Brachet Contul R and Garrone C: Laparoscopic total mesorectal excision: a consecutive series of 100 patients. Ann Surg 237: 335-342, 2003.

17 Bianchi PP, Rosati R, Bona S, Rottoli M, Elmore U, Ceriani C, Malesci A and Montorsi M: Laparoscopic surgery in rectal cancer: A prospective analysis of patient survival and outcomes. Dis ColonRectum 50: 2047-2053, 2007.

18 Zhou ZX, Zhao LY, Lin T, Liu H, Deng HJ, Zhu HL, Yan J and Li GX: Long-term oncologic outcomes of laparoscopic vs. open surgery for stages II and III rectal cancer: A retrospective cohort study. World J Gastroenterol 21: 5505-5512, 2015.

19 Huang C, Shen JC, Zhang J, Jiang T, Wu WD, Cao J, Huang KJ and Qiu ZJ: Clinical comparison of laparoscopy $v s$. open surgery in a radical operation for rectal cancer: A retrospective case-control study. World J Gastroenterol 21: 13532-13541, 2015.

20 Li S, Jiang F, Tu J and Zheng X: Long-term oncologic outcomes of laparoscopic versus open surgery for middle and lower rectal cancer. PLos ONE 10: e0135884, 2015.

21 Staudacher C, Di Palo S, Tamburini A, Vignali A and Orsenigo E: Total mesorectal excision (TME) with laparoscopic approach: 226 consecutive cases. Surg Oncol 16: 113-116, 2007.

22 Ng SS, Leung KL, Lee JF, Yiu RY, Li JC, Teoh AY and Leung WW: Laparoscopic-assisted versus open abdominoperineal resection for low rectal cancer: a prospective randomized trial. Ann Surg Oncol 15: 2418-2425, 2008.

$23 \mathrm{Ng} \mathrm{KH}, \mathrm{Ng}$ DC, Cheung HY, Wong JC, Yau KK, Chung CC and Li MK: Laparoscopic resection for rectal cancers: lessons learned from 579 cases. Ann Surg 249: 82-86, 2009. 
24 Sun J, Jiang T, Qiu Z, Cen G, Cao J, Huang K, Pu Y, Liang H, Huang $\mathrm{R}$ and Chen S: Short-term and medium-term clinical outcomes of laparoscopic-assisted and open surgery. For colorectal cancer: a single center retrospective case-control study. BMC Gastroenterol 11: 85, 2011.

25 Nagtegaar ID and Quirke P: What is the role for the circumferential margin in the modern treatment of rectal cancer?. J Clin Oncol 26: 303-312, 2008.

26 Larsen SG, Wiig JN, Emblemsvaag HL, Grøholt KK, Hole KH, Bentsen A, Dueland S, Vetrhus T and Giercksky KE: Extended total mesorectal excision in locally advanced rectal cancer (T4a) and the clinical role of MRI-evaluated neo-adjuvant downstaging. Colorectal Dis 11: 759-767, 2009.

27 Aziz O, Constantinides V, Tekkis PP, Athanasiou T, Purkayastha S, Paraskeva P, Darzi AW and Heriot AG: Laparoscopic versus open surgery for rectal cancer: A meta-analysis. Ann Surg Oncol 13: 413-424, 2006.

28 Gao F, Cao YF and Chen LS: Meta-analysis of short-term outcomes after laparoscopic resection for rectal cancer. Int $\mathbf{J}$ Colorectal Dis 21: 652-656, 2006.

29 Lacy AM, García-Valdecasas JC, Delgado S, Castells A, Taurá P, Piqué JM and Visa J: Laparoscopy-assisted colectomy versus open colectomy for treatment of non-metastatic colon cancer: A randomised trial. Lancet 359: 2224-2229, 2002.
30 Lacy AM, Delgado S, Castells A, Prins HA, Arroyo V, Ibarzabal A and Pique JM: The long-term results of a randomized clinical trial of laparoscopy-assisted versus open surgery for colon cancer. Ann Surg 248: 1-7, 2008.

31 Leung KL, Tsang KS, Ng MH, Leung KJ, Lai PB, Lee JF and Lau WY: Lymphocyte subsets and natural killer cell cytotoxicity after laparoscopically assisted resection of rectosigmoid carcinoma. Surg Endosc 17: 1305-1310, 2003.

32 Leung KL, Lai PB, Ho RL, Meng WC, Yiu RY, Lee JF and Lau WY: Systemic cytokine response after laparoscopic assisted resection of rectosigmoid carcinoma: a prospective randomized trial. Ann Surg 231: 506-511, 2000.
Received August 18, 2016

Revised September 3, 2016 Accepted September 5, 2016 